\title{
Pearls \& Oy-sters: Driving Safety in Photosensitive Genetic Generalized Epilepsy
}

Mohamed Nasser, MD, and Zubeda Sheikh, MD

Neurology ${ }^{\circledR}$ 2021;97:e1057-e1059. doi:10.1212/WNL.0000000000012157
Correspondence

Dr. Sheikh

zubeda.karim@gmail.com

\section{Pearls}

- "Subclinical" generalized epileptiform discharges in patients with generalized epilepsy may be associated with transitory cognitive impairment upon appropriate testing. ${ }^{1-4}$ Increased reaction time is the most sensitive behavioral correlate to these discharges. ${ }^{3,4}$

- Duration of generalized spike-wave discharges is a likely determinant of increased reaction time and cognitive impairment. Discharges longer than 2-3 seconds are associated with increased reaction time, ${ }^{1,3,4}$ and these may imply the necessity for further evaluation of driving ability.

\section{Oy-sters}

- About 5\% of people with epilepsy have evidence of photosensitivity on EEG; a third of these have visually induced seizures. ${ }^{5}$ Driving in certain environmental conditions (tunnels, sunlight breaking up along a tree-lined road) may produce flash frequencies that may precipitate seizures. ${ }^{6}$

- A particular type of lens called the Z1 lens blocked photoparoxysmal response (PPR) in $76 \%$ of patients. ${ }^{7}$ Due to the lack of availability of these in North America, polarized blue lenses with low transmittance may be used to attempt to block the PPR.

- Photic stimulation in the laboratory with and without polarized blue lenses may help evaluate safety during driving in patients with photosensitive generalized epilepsy.

We saw a 22-year-old woman with juvenile myoclonic epilepsy who had onset at age 15 with photosensitive myoclonic jerks and bilateral tonic-clonic seizures. She required evaluation of her ability to drive. Her last bilateral tonic-clonic seizure (triggered by flashes of sunlight through the trees while riding in a car) was 7 months before evaluation. She had met the state regulations of 6 months of seizure freedom required to drive legally. However, due to concerns about a generalized epilepsy syndrome with photosensitivity, additional evaluation was requested by the epileptologist.

We requested an EEG to look for generalized spike-wave bursts during wakefulness that may impair consciousness or increase reaction time especially during photic stimulation. We had advised the patient to buy polarized blue sunglasses for this evaluation. The EEG showed sporadic generalized spike/polyspike-wave discharges, lasting $0.25-0.5$ seconds during awake and sleep states. Photic stimulation at 10,15 , and $20 \mathrm{~Hz}$ was stopped at $2-3$ seconds due to bursts of generalized frontally predominant, $2-3 \mathrm{~Hz}$ polyspike wave discharges that started with the stimulation (figure, A and B). During these bursts, her concentration and gross and fine motor functions were intact. For gross and fine motor testing, the patient was instructed before each run of photic stimulation to hold her arms up while tapping the thumb against the index finger and counting backward from 50 at the same time. No myoclonic jerks were seen during the bursts. Photic stimulation was repeated and completed at $3,8,10,12,15,20$, and $30 \mathrm{~Hz}$ with the patient wearing the polarized blue sunglasses. The photoparoxysmal response (PPR) seen without sunglasses was not seen while wearing sunglasses (figure, $C$ and D). As the PPR was aborted with polarized blue sunglasses, she was determined safe to resume driving, and we 

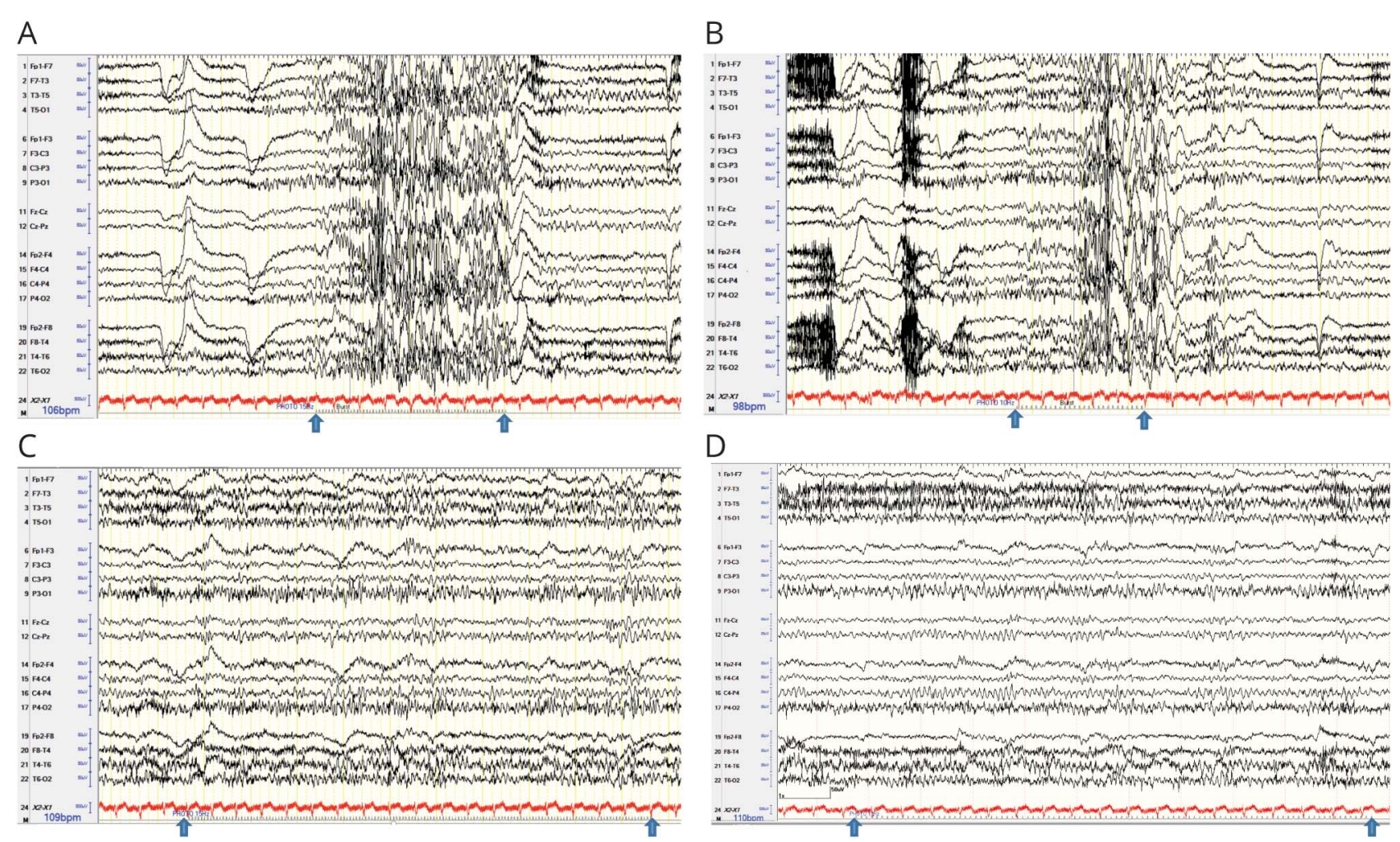

(A, B) EEG in the longitudinal bipolar montage shows photoparoxysmal response characterized by a burst of generalized polyspike wave discharges at $2.5 \mathrm{~Hz}$ lasting 2-3 seconds at $15 \mathrm{~Hz}(\mathrm{~A})$ and $10 \mathrm{~Hz}$ (B) photic stimulation. (C, D) EEG in the longitudinal bipolar montage and photic stimulation at $15 \mathrm{~Hz}$ (C) and $10 \mathrm{~Hz}$ (D) with the patient wearing blue polarized sunglasses that prevent the occurrence of photoparoxysmal response in the same patient during the same recording (A-D) Blue arrows mark the onset and offset of photic flash frequencies. All EEGs were clipped at sensitivity of $7 \mu \mathrm{V} / \mathrm{mm}$, low frequency filter of $1.6 \mathrm{~Hz}$, high frequency filter of $70 \mathrm{~Hz}$, and $60 \mathrm{~Hz}$ filter (notch) turned off.

instructed her to wear polarized blue sunglasses during driving. Although her concentration and motor ability were intact during the photoparoxysmal bursts, this testing was limited to up to 3 seconds of bursts; further, we did not record reaction time quantitatively.

\section{Discussion}

Generalized spike-wave discharges can occur on EEG without a clinical accompaniment of absence seizures, the so-called "subclinical" discharges. Many studies have shown that with better clinical testing, transitory cognitive impairment, manifest most commonly as increased reaction time, accompanies these seemingly subclinical discharges. ${ }^{1-4}$

In early experiments from the 1940s, the discharge bursts lasting 1-3 seconds had normal reaction times, and longer bursts showed impairment. ${ }^{1}$ Nevertheless, some other studies showed an increase in reaction time even with short bursts lasting $0.5-1.5$ seconds; however, there was no increase in errors of omission during such short bursts. ${ }^{3}$ Another study showed that the initial 3 seconds and the final 1.5 seconds were associated with less consciousness impairment than the intervening period. ${ }^{2}$ All these studies were limited mainly by sample size ( $\mathrm{n}=1$ to 8 ) and varying methods of testing consciousness. More recently, a pilot study of driving simulation in people with generalized spike-wave discharges showed correlation of lack of response to stimulation with the duration and amplitude of spike-wave discharges. This pilot study showed that generalized spike-wave discharges with no response to stimuli were significantly longer than those with appropriate responses $(8.47 \pm 3.10$ vs $1.85 \pm 0.69$ seconds, $p<0.001) .{ }^{4}$ Again, the study had a low sample size of 9 although 88 bursts were studied. Although the data regarding this are limited, as discussed above, there is a suggestion of correlation of transitory cognitive impairment with duration of generalized spike-wave bursts.

Transitory cognitive impairment is of clinical importance, especially when it poses a risk for injury or death; the most common scenario is driving a motor vehicle. Hence testing for impairment of consciousness becomes important in a patient who has generalized spike-wave discharges without overt absences. The effect of duration of generalized spike-wave discharges on driving ability was shown in a recent study with high fidelity driving simulator; reaction times to stimulation correlated with the duration of generalized spike-wave bursts. ${ }^{4}$ We tested our patient with gross motor, fine motor, and a concentration task, as described above; we found no impairment in these tasks during the photoparoxysmal bursts. However, we did not record reaction times, and we aborted photic stimulation at $\sim 3$ seconds. Longer duration bursts 
might have caused impairment if we did not abort the photic stimulation. For this reason, we tested the patient's flashing light tolerance with polarized blue sunglasses on and could complete photic stimulation without the occurrence of any PPR.

About 5\% of people with epilepsy have evidence of photosensitivity on EEG, and about a third of these have visually induced seizures. ${ }^{5}$ Certain environmental factors cause a flashing effect during driving; these include sunlight breaking up along a tree-lined road, acoustic barrier posts interrupting the sunlight, and noise barrier tunnels with a transparent roof. ${ }^{6}$ Various lenses have been tested that could effectively block the flashing light frequencies and prevent photosensitive seizures. The efficacy depends on lens color and transmittance. ${ }^{8-10}$ Eighty-three patients were tested to suppress photosensitivity during intermittent photic stimulation by using different types of lenses. A type of lens named Z1 was found to be significantly more effective in blocking photosensitivity effectively, compared to the other lenses. ${ }^{10} \mathrm{Z} 1$ is a blue lens of an ultraviolet material with an $80 \%$ luminance cut. Subsequently, a large multicenter study showed the disappearance of PPR with the use of $\mathrm{Z1}$ lenses in $76 \%$, and the response was considerably reduced in an additional $18 \%$. PPR remained unchanged in only $6 \% .^{7}$ These lenses are commercially available in Italy. Due to the lack of availability of this particular lens type, we tested our patient with polarized blue sunglasses ${ }^{8}$; this aborted the PPR. We were able to advise the patient that she is safe to drive with the polarized blue sunglasses on.

Blue and polarized sunglasses (any commercially available ones) may have efficacy in curtailing photosensitivity in people with epilepsy; efficacy of these must be tested in the EEG laboratory in the setting of evaluation of ability to drive. Further studies are needed to evaluate whether the efficacy is consistent with repeat stimulations, especially in the setting of higher epileptogenicity such as sleep deprivation or antiseizure medication withdrawal.

\section{Study Funding}

No targeted funding reported.

\section{Disclosure}

The authors have no disclosures to report. Go to Neurology. org/ $\mathrm{N}$ for full disclosures.

\section{Appendix Authors}

\begin{tabular}{lll}
\hline Name & Location & Contribution \\
\hline $\begin{array}{l}\text { Mohamed } \\
\text { Nasser, } \\
\text { MD }\end{array}$ & $\begin{array}{l}\text { Department of Neurology, } \\
\text { West Virginia University } \\
\text { School of Medicine, } \\
\text { Morgantown }\end{array}$ & $\begin{array}{l}\text { Initial manuscript draft and } \\
\text { figure creation }\end{array}$ \\
\hline $\begin{array}{l}\text { Zubeda } \\
\text { Sheikh, } \\
\text { MD }\end{array}$ & $\begin{array}{l}\text { Department of Neurology, } \\
\text { West Virginia University }\end{array}$ & $\begin{array}{l}\text { Concept and design, } \\
\text { manuscript and figure revision } \\
\end{array}$ \\
$\begin{array}{l}\text { School of Medicine, } \\
\text { Morgantown }\end{array}$ & \\
\hline
\end{tabular}

\section{References}

1. Schwab RS. The influence of visual and auditory stimuli on electroencephalographic tracing of petit mal. Am J Psychiatry. 1941;97(6):1301-1312

2. Goldie L, Green JM. Spike and wave discharges and alterations of conscious awareness. Nature. 1961;191:200-201.

3. Tizard B, Margerison JH. The relationship between generalized paroxysmal EEG discharges and various test situations in two epileptic patients. J Neurol Neurosurg Psychiatry. 1963;26(4):308-313.

4. Cohen E, Antwi P, Banz BC, et al. Realistic driving simulation during generalized epileptiform discharges to identify electroencephalographic features related to motor vehicle safety: feasibility and pilot study. Epilepsia. 2020;61(1):19-28.

5. Quirk JA, Fish DR, Smith SJ, Sander JW, Shorvon SD, Allen PJ. Incidence of photosensitive epilepsy: a prospective national study. Electroencephalogr Clin Neurophysiol. 1995;95(4):260-267.

6. Dondi G, Vignali V, Lantieri C, Manganelli G. Effects of flickering seizures on road drivers and passengers. Proc Soc Behav Sci. 2012;53(3):711-720.

7. Capovilla G, Gambardella A, Rubboli G, et al. Suppressive efficacy by a commercially available blue lens on PPR in 610 photosensitive epilepsy patients. Epilepsia. 2006; 47(3):529-533.

8. Takahashi T, Tsukahara Y. Usefulness of blue sunglasses in photosensitive epilepsy. Epilepsia. 1992;33(3):517-521.

9. Capovilla G, Dalla Bernardina B. Suppressive effect upon photoparoxysmal response using experimental blue sunglasses in pediatric age. Boll Lega It Epilepsy. 1994;87/ 88(3):439-440

10. Capovilla G, Beccaria F, Romeo A, Veggiotti P, Canger R, Paladin F. Effectiveness of a particular blue lens on photoparoxysmal response in photosensitive epileptic patients. Ital J Neurol Sci. 1999;20(3):161-166. 


\section{Neurology}

\section{Pearls \& Oy-sters: Driving Safety in Photosensitive Genetic Generalized Epilepsy Mohamed Nasser and Zubeda Sheikh}

Neurology 2021;97;e1057-e1059 Published Online before print May 4, 2021

DOI 10.1212/WNL.0000000000012157

This information is current as of May 4, 2021

\section{Updated Information \& Services}

References

Subspecialty Collections

Permissions \& Licensing

Reprints including high resolution figures, can be found at: http://n.neurology.org/content/97/10/e1057.full

This article cites 10 articles, 1 of which you can access for free at: http://n.neurology.org/content/97/10/e1057.full\#ref-list-1

This article, along with others on similar topics, appears in the following collection(s): EEG; see Epilepsy/Seizures http://n.neurology.org/cgi/collection/eeg_see_epilepsy-seizures

Information about reproducing this article in parts (figures,tables) or in its entirety can be found online at:

http://www.neurology.org/about/about_the_journal\#permissions http://n.neurology.org/subscribers/advertise

Neurology ${ }^{\circledR}$ is the official journal of the American Academy of Neurology. Published continuously since 1951, it is now a weekly with 48 issues per year. Copyright () 2021 American Academy of Neurology. All rights reserved. Print ISSN: 0028-3878. Online ISSN: 1526-632X.

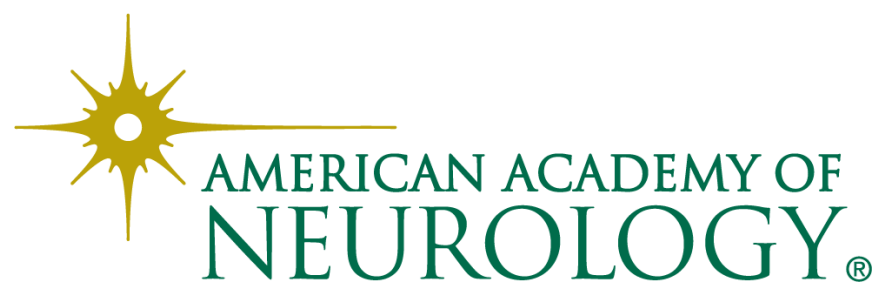

